\title{
CLINICAL RESEARCH
}

\section{Pregnancy induced hypertension: evidence for increased cell membrane permeability to sodium}

\author{
P L WEISSBERG, J WEAVER, K L WOODS, M J WEST, D G BEEVERS
}

\begin{abstract}
In a cross sectional study of 137 women of childbearing age (16-40) the effects of normal pregnancy, hypertensive pregnancy, and oral contraceptives on red cell electrolyte content and sodium efflux rates were examined and the results compared with values in a control group of normotensive, non-pregnant women. Efflux rate constants were significantly increased in normotensive pregnancy and in women taking oral contraceptives. This was associated with a significant increase in sodium permeability in the contraceptive group. A much larger increase in sodium permeability and efflux rate constant was seen in the hypertensive group.

The results permit a hypothesis that the hormonal changes induced by pregnancy and oral contraceptives increase membrane permeability to sodium and stimulate sodium efflux. The rise in blood pressure associated with use of oral contraceptives may have a similar aetiology to that occurring in pregnancy induced hypertension.
\end{abstract}

\section{Introduction}

In normal pregnancy peripheral resistance is not raised despite high circulating concentrations of angiotensin II; in hypertensive pregnancy, however, this protection against the effects of angiotensin II is lost, resulting in arterial vasoconstriction and an increase in blood pressure.' Little is known of the cellular

\footnotetext{
The Medical School, University of Birmingham, Edgbaston, Birmingham B15 2TJ

P L WEISSBERG, MB, MRCP, Sheldon research fellow, department of therapeutics and clinical pharmacology

J WEAVER, FRCS, MRCOG, consultant obstetrician

$\mathrm{K} L$ WOODS, MD, MRCP, lecturer in therapeutics and clinical pharmacology $M \mathrm{~J}$ WEST, BSC, research technician

D G BEEVERS, MD, FRCP, senior lecturer in medicine

Correspondence to: Dr P L Weissberg.
}

mechanisms underlying these changes, although a similar abnormality to that described in essential hypertension ${ }^{2}$ has been proposed. ${ }^{3}$ We have studied the electrolyte content and sodium efflux rates in erythrocytes from normotensive and hypertensive pregnancies and compared them with values in non-pregnant women receiving no medication and a group taking oral contraceptives. Our aim was to establish if there was an abnormality of sodium handling which might precipitate hypertension.

\section{Subjects and methods}

We studied 137 white women comprising the following groups: 15 non-pregnant women not taking oral contraceptives (controls); nine women taking oral contraceptives; 16 normotensive women in the first trimester of pregnancy; 37 normotensive women in the second trimester of pregnancy; 51 normotensive women in the third trimester of pregnancy; and nine hypertensive women in the third trimester of pregnancy. Plasma and intracellular sodium and potassium concentrations were measured in all subjects. Sodium efflux rate constants were measured in all non-pregnant and hypertensive pregnant women and in 12 normotensive women in the third trimester. None of the subjects studied had a family history of hypertension or had been taking antihypertensive agents. Pregnancy induced hypertension was defined as a persistently raised blood pressure above $140 / 90 \mathrm{~mm} \mathrm{Hg}$ occurring in a previously normotensive woman. All were normotensive six weeks after delivery. Blood pressures were measured in the normotensive pregnant women during a routine antenatal visit using standard mercury sphygmomanometers, and in the non-pregnant women by a different observer using a random zero sphygmomanometer. All hypertensive subjects were inpatients admitted for control of their blood pressure, and hypertension was confirmed using a random zero machine. Control subjects consisted of normotensive women with the same age distribution as the pregnant women.

Intracellular electrolytes were measured by a method designed to minimise errors arising from contamination by extracellular electrolytes and changes in cell water. ${ }^{4}$ Intracellular and plasma electrolytes were measured by flame photometry (Instrumentation Laboratories 543).

Sodium efflux was measured in red cells incubated for one hour at $37^{\circ} \mathrm{C}$ in their own plasma containing $10 \mu \mathrm{Ci}{ }^{22} \mathrm{Na}$ (Amersham International). After washing off extracellular isotope with isotonic saline solution the cells were resuspended in their own isotope free plasma for one hour at $37^{\circ} \mathrm{C}$. Duplicate experiments were done with and without ouabain. The rate of appearance of ${ }^{22} \mathrm{Na}$ in the plasma 
without ouabain gave the total sodium efflux rate constant. Sodium pump activity was derived from the difference between the two (with and without ouabain). The product of the efflux rate constant and intracellular sodium value gave the unidirectional sodium efflux in $\mathrm{mmol}(\mathrm{mEq}) / \mathrm{kg} / \mathrm{h}$. All experiments were performed on fresh samples of blood. Statistical analysis was by Student's $t$ test for plasma and intracellular electrolytes, and by Mann-Whitney $U$ test for flux data.

\section{Results}

The groups were well matched for age. Systolic blood pressure was higher in women taking oral contraceptives than in controls but this did not reach statistical significance (table I).

Plasma electrolytes (table II)-Both the plasma sodium concentration and plasma potassium concentration were significantly lower throughout pregnancy compared with values in controls and women taking oral contraceptives.

Intracellular electrolytes (table II)-In normal pregnancy there was a fall in intracellular sodium, which was significant in the second trimester compared with controls. Intracellular sodium concentration was not significantly higher in hypertensive women in the third trimester than in normotensive women in the third trimester. Intracellular potassium concentration was significantly lower in all stages of normotensive pregnancy compared with controls but was the same as controls in the hypertensive women in the third trimester; the difference in values between normotensive and hypertensive women in the third trimester, however, was not significant.

Sodium efflux (table III)-Total sodium efflux rate constant was higher in the normotensive women in the third trimester than in the controls with a significant increase in both ouabain sensitive and ouabain insensitive components. In the hypertensive women the total efflux rate constant was very much greater than in the normotensive women in the third trimester, due mostly to a large increase in sodium pump activity. Total efflux rate constant in those taking oral contraceptives was significantly higher than in controls, though only the ouabain insensitive component reached significance owing to a large variation in this group.

Unidirectional sodium efflux (table III) showed no difference between the controls and normotensive women in the third trimester, but in the group taking oral contraceptives and in the hypertensive women in the third trimester it was significantly raised.

\section{Discussion}

The fall in plasma electrolyte concentration reflects the expanded plasma volume associated with normal pregnancy. ${ }^{5}$ The higher systolic blood pressures recorded during the first and second trimesters of pregnancy could not be compared with control values because of the different circumstances under which they were measured.

We have shown that normotensive pregnancy is associated with an increased rate of sodium efflux. Although the total efflux rate constant was raised, the unidirectional sodium flux was not, suggesting that the membrane permeability to sodium remains normal. In hypertensive pregnancy both total efflux rate constant, and unidirectional sodium flux were greatly increased, suggesting an increased permeability to sodium. These results imply that the hormonal changes associated with normal pregnancy stimulate sodium efflux, causing intracellular sodium concentrations to fall. Such changes have also been found by other investigators. ${ }^{6}$

Our results also show that despite a large increase in membrane permeability to sodium in the hypertensive group, intracellular electrolyte concentrations remained remarkably stable, suggesting that the cells are capable of responding to the increased permeability by increasing their ability to pump out sodium. Because this was not a longitudinal study the fact that the hypertensive group did not have a significantly raised intracellular sodium concentration as a whole does not rule out the possibility that subjects within the group might have had important increases in intracellular sodium over the course of their pregnancy.

The increase in membrane permeability to sodium found in the hypertensive group might have been due to a circulating toxic substance; however, that permeability is also increased by

TABLE I-Details of age and blood pressure distributions in the six groups studied

\begin{tabular}{lccccc}
\hline & \multicolumn{1}{c}{$\begin{array}{c}\text { Pill users } \\
(\mathrm{n}=9)\end{array}$} & $\begin{array}{c}\text { Controls } \\
(\mathrm{n}=15)\end{array}$ & $\begin{array}{c}\text { 1st trimester } \\
(\mathrm{n}=16)\end{array}$ & $\begin{array}{c}\text { 2nd trimester } \\
(\mathrm{n}=37)\end{array}$ & $\begin{array}{c}\text { 3rd trimester } \\
(\mathrm{n}=51)\end{array}$ \\
\hline $\begin{array}{l}\text { Mean age in years } \\
(\mathrm{range}) \\
\begin{array}{c}\text { Mean blood pressure } \\
(\mathrm{SD}) \text { in mm Hg }\end{array}\end{array}$ & $24 \cdot 0(21-29)$ & $25 \cdot 0(20-37)$ & $26 \cdot 9(19-37)$ & $27 \cdot 1(16-37)$ & $26 \cdot 0(17-39)$ \\
\hline
\end{tabular}

TABLE II-Mean plasma and intracellular electrolyte values (SEM given in parentheses)

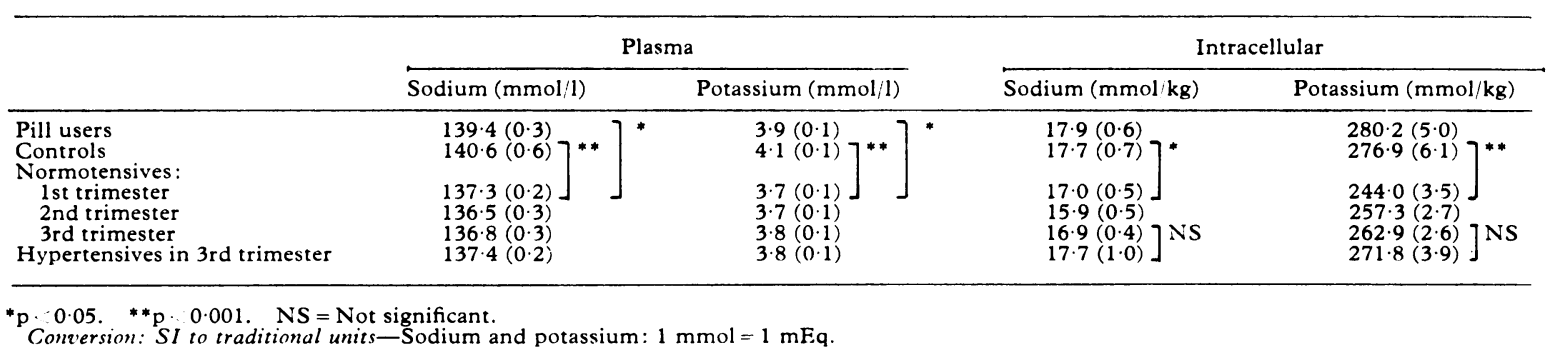

TABLE III-Results of efflux rate constants $(E R C)$ and unidirectional sodium flux (ERC $\times$ intracellular Na) (SD given in parentheses)

\begin{tabular}{|c|c|c|c|c|}
\hline & Total ERC/h & $\begin{array}{l}\text { Ouabain sensitive } \\
\text { ERC/h }\end{array}$ & $\begin{array}{l}\text { Ouabain insensitive } \\
\text { ERC } / \mathrm{h}\end{array}$ & $\begin{array}{l}\text { Unidirectional sodium flux } \\
(\mathrm{mmol} / \mathrm{kg} / \mathrm{h})\end{array}$ \\
\hline $\begin{array}{l}\text { Pill users }(n=9) \\
\text { Controls }(n=15)\end{array}$ & $\begin{array}{l}0.660((\cdot .190)]^{*} \\
0.514(0.133)]^{* *}\end{array}$ & $\begin{array}{l}0.448(0.157)] \mathrm{NS} \\
0.353(0.166){ }^{*}\end{array}$ & $\begin{array}{l}0.212(0.051) \\
0.161(0.030)]^{* *}\end{array}$ & $\begin{array}{l}11 \cdot 6(2 \cdot 6)]^{*} \\
9 \cdot 1(2 \cdot 6)\end{array}$ \\
\hline Normotensives in 3rd trimester $(\mathrm{n}=12)$ & $0.629(0.987)]^{* * *}$ & $0.421(0.074)]^{* * *}$ & $0.209(0.038) J^{* *}$ & $10 \cdot 4(2 \cdot 3)\{* *$ \\
\hline Hypertensives in 3rd trimester $(n=9)$ & $0.832(0.106)]$ & $0.571(0.104)]$ & $0.260(0.049)]$ & $14.5(1 \cdot 7)]$ \\
\hline
\end{tabular}

$*$ p $<0.05 . \quad * * \mathrm{p}-0.01 . \quad * * * \mathrm{p} .0001 . \quad \mathrm{NS}=$ Not significant

Conversion: SI to traditional imits-Sodium flux: $1 \mathrm{mmol} / \mathrm{kg} / \mathrm{h}=1 \mathrm{mEq} / \mathrm{kg} / \mathrm{h}$ 
oral contraceptives makes this unlikely. An alternative explanation is that the hormonal changes induced by pregnancy and oral contraceptives cause an increase in membrane permeability to sodium and stimulate sodium efflux. If this were the case then there must be an agent present in normal pregnancy which stabilises the cell membrane and which is absent or diminished in hypertensive pregnancy.

It has been suggested that prostacyclin mediates the tolerance to angiotensin II in normal pregnancy and that its relative lack is responsible for the onset of hypertension. ${ }^{7}$ This hypothesis is compatible with our results, since it has also been found that oral contraceptives inhibit prostacyclin production, ${ }^{8}$ and that long term use of oral contraceptives is associated with a significant and reversible rise in blood pressure. ${ }^{9}$ Our results offer an explanation for this phenomenon, since the increased cell membrane permeability to sodium occurring in women taking oral contraceptives was similar to that occurring in hypertensive pregnancy. Indeed it has been suggested that women most likely to have a rise in blood pressure while taking the pill are those who have had pre-eclampsia. ${ }^{1011}$

In order properly to evaluate the hormonal influences of pregnancy and oral contraceptives on cellular sodium handling longitudinal studies are required so that changes within subjects can be monitored.

This study was partly supported by a grant from the Central Birmingham Health District Endowment Research Committee.

\section{References}

1 Gant NF, Daley GL, Chand S, Macdonald PC. A study of angiotensin II pressor response throughout primigravid pregnancy. 7 Clin Invest 1973;52:2682-9.

${ }^{2}$ Edmondson RPS, Hilton PJ, Thomas RD, Patrick J, Jones NF. Abnormal leucocyte composition and sodium transport in essential hypertension. Lancet $1975 ; \mathrm{i}: 1003-5$.

${ }^{3}$ Forrester TE, Alleyne AO. Leucocyte electrolytes and sodium efflux rate constants in hypertension of pre-eclampsia. Clin Sci 1980;59:199s-201s.

- Weissberg PL, West MJ, Woods KL. An improved method for measuring intracellular electrolytes in erythrocytes and the effects of cold storage. Clin Chim Acta 1983;129:85-9.

${ }^{6}$ Hytten FE, Thomson AM, Taggart M. Total body water in normal pregnancy. Fournal of Obstetrics and Gynaecology of the British Commonwealth 1966;73:553-61.

${ }^{6}$ Rubython J, Morgan DB. The effect of pregnancy and pregnancy induced hypertension on active sodium transport in the erythrocyte. Clin Sci $1983 ; 64: 57 \mathrm{P}$

7 Broughton Pipkin F, Hunter JC, Turner SR, O'Brien PMS. Prostaglandin $\mathrm{E}_{2}$ attenuates the pressor response to angiotensin II in pregnant subjects but not in non-pregnant subjects. Am $\mathcal{F}$ Obstet Gynecol 1982;142:168-76.

* Ylikorkala O, Puolakkaj, Vhnikka L. The effect of oral contraceptives on anti-aggregatory prostacyclin and pro-aggregatory thromboxane $\mathrm{A}_{2}$ in humans. Am f Obstet Gynecol 1982;142:573-6.

${ }^{9}$ Weir RJ, Briggs E, Mack A, Naismith L, Taylor L, Wilson E. Blood pressure in women taking oral contraceptives. Br Med F 1974;i:533-5.

10 Spellacy WN, Birk SA. The effects of intrauterine devices, oral contraceptives, estrogens, and progestogens on blood pressure. Am $\mathcal{f}$ Obstet Gynecol 1972;112:912-9.

1 Clezy TM, Foy BN, Hodge RL, Lumbers ER. Oral contraceptives and hypertension. Br Heart $\mathcal{F} 1972 ; 34: 1238-43$.

(Accepted 1 fune 198.3)

\title{
Intermittent cyclophosphamide in refractory rheumatoid arthritis
}

\author{
KIM HØRSLEV-PETERSEN, JANNIE M BEYER, PEKKA HELIN
}

\begin{abstract}
Three patients with refractory rheumatoid arthritis were treated with oral cyclophosphamide; in two cases this was supplemented with pulse treatment with methylprednisolone. Long term remission was induced in all three patients and was sustained until follow up at least nine months after the methylprednisolone was stopped. Leucopenia occurred but resolved when cyclophosphamide was reduced from daily to intermittent dosing.

Intermittent treatment with cyclophosphamide, possibly in conjunction with pulses of methylprednisolone, may induce remission in patients with rheumatoid arthritis refractory to other forms of treatment.
\end{abstract}

\section{Introduction}

Recently the possibility of managing refractory rheumatoid arthritis has increased with the availability of various immuno-

\footnotetext{
Department of Rheumatology, Kong Christian den X's Gigthospital, DK-6300 Graasten, Denmark

KIM HORSLEV-PE TERSEN, MD, registrar

JANNIE $M$ BEYER, MD, senior house officer

PEKKA HELIN, MD, PHD, head of department

Correspondence to: Dr K Horslev-Petersen.
}

suppressive regimens, among them cytostatic treatment and intravenous methylprednisolone pulse treatment. Use of a combination of corticosteroids and intermittent cytostatic treatment, which is well established in treating cancer, ${ }^{1}$ has not been described in rheumatoid arthritis resistant to treatment, although Fosdick et al reported using intermittent cyclophosphamide treatment in a few patients with rheumatoid arthritis. ${ }^{2}$

We report the effect of combined intermittent cyclophosphamide treatment and methylprednisolone in three patients with disabling rheumatoid arthritis that had been impossible to control adequately either because of toxic side effects or because of failure to respond to treatment.

\footnotetext{
Case reports

Case 1-A 60 year old woman with seropositive erosive rheumatoid arthritis of four years' duration had been treated with low dose prednisone, gold, and penicillamine. In July 1981, as disease activity persisted (table), oral cyclophosphamide was started at a dose of $100 \mathrm{mg} /$ day, which was reduced to $50 \mathrm{mg} /$ day when leucopenia $\left(2.9 \times 10^{9} / 1\right)$ occurred. As the leucopenia continued intermittent treatment with cyclophosphamide $100 \mathrm{mg}$ every three and subsequently every four days was begun, which completely abolished the symptoms. In May 1983 the disease was still in remission (table).

Case 2-A 51 year old woman with seropositive erosive rheumatoid arthritis of six years' duration had received treatment with gold, chloroquine, penicillamine, and azathioprine. As her disease remained active (table), in September 1981 she was placed on a regimen of methylprednisolone pulse treatment $1 \mathrm{~g}$ intravenously on four successive days and oral cyclophosphamide $100 \mathrm{mg} /$ day. As the disease activity did not abate, repeated courses of methylprednisolone pulse
} 